\title{
STATISTICAL ANALYSIS OF APPLICATION OF AHP IN POSTGRADUATE THESIS OF TSINGHUA UNIVERSITY
}

\author{
Ming Yu \\ (Department of Industrial Engineering, Tsinghua University, \\ Beijing 100084, China, mingyu@mail.tsinghua.edu.cn) \\ Erjiang E \\ (Department of Industrial Engineering, Tsinghua University, \\ Beijing 100084, China, eej17@mails.tsinghua.edu.cn)
}

\begin{abstract}
Analytic hierarchical process (AHP) is an efficient tool used multiple criteria decision making. This paper gives an overview of applications of analytical hierarchical process (AHP) in various areas. We collect 176 doctoral and master these using AHP from 1986 to 2017 in Tsinghua University. This paper analyzes the application of AHP approach in various disciplines, industries, and fields.
\end{abstract}

Keywords: Analytic hierarchical process, Application analysis, Doctoral thesis, Master thesis

\section{Introduction}

Multi-criteria decision making (MCDM) is one of the most well-known branches of decision making (Triantaphyllou, 2000). In 1980, Saaty proposed the analytic hierarchical process (AHP) which is an efficient tool to deal with complex decision making problems. This method is one of the MCDM approaches and widely used by decision makers and researchers. Some scholars have given a literature review of the AHP application. Davies (2001) gives a review of marketing applications of adaptive AHP. His paper aims to report on 1) variations to standard or classical AHP that can help solve marketing problems and offer guidance to users; 2) how these variations may be used within a marketing knowledge-based decision support system. Russo and Camanho (2015) also give a review of literature on real cases that applied AHP to evaluate how the criteria are being defined and measured. Singh (2016) finds that AHP approach not only applied in management field, but also used in other fields like business and marketing, design, environment, agriculture, development, healthcare, banking, manufacturing, construction and other complex decision making tasks.

In this paper, we focus on application analysis of AHP based on the cases of 6 doctoral these and 170 master's these in Tsinghua University (THU). These theses have adopted AHP approach as a research tool to solve practical problems. Firstly, we will discuss the application of AHP approach in various disciplines and analyze which disciplines prefer this method. Then, this paper analyzes the application of AHP approach in various industries. Finally, we separate the theses into appropriate areas or fields. 


\section{Statistical Analysis}

\subsection{Sources of Literature}

The literatures are taken from electronic theses and dissertations service of Tsinghua University ${ }^{1}$. We collect 180 postgraduate theses using the multi-criteria decision making approaches including AHP, analytic network process (ANP), grey relation analysis (GRA), simple additive weighting (SAW), technique for order preference by similarity to an ideal solution (TOPSIS), elimination and choice expressing reality (ELECTRE). We find that 170 theses using AHP approach, 6 theses using the methods combined AHP and other MCDM approaches, 4 theses using MCDM approaches except for AHP. Fig. 1 shows the number of theses from 1986 to 2017, including 6 doctoral theses and 170 master theses. It means that AHP approach is gaining growing popularity comparing with other MCDM approaches.

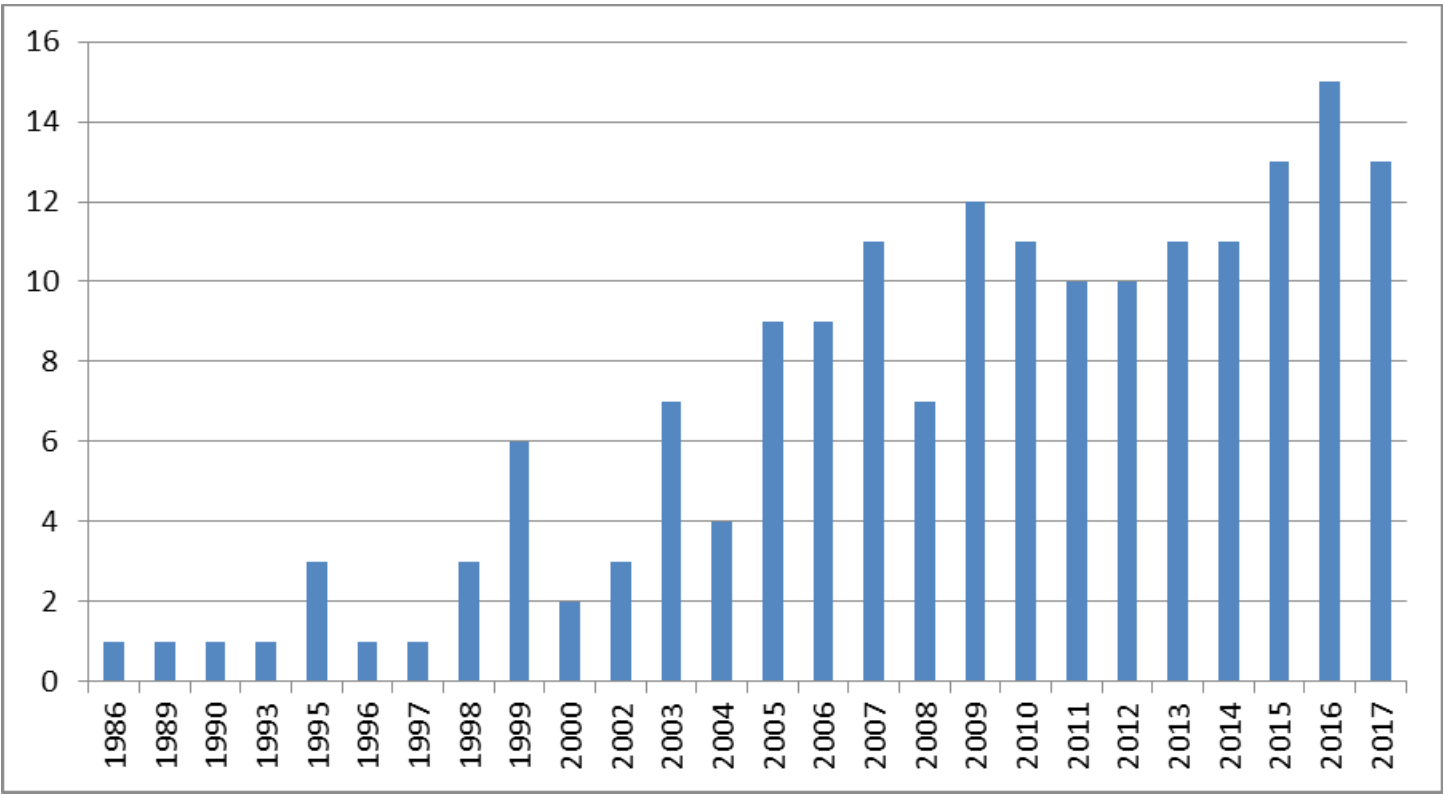

Fig.1 The number of doctoral and master theses using AHP from 1986 to 2017 in THU

\subsection{Disciplines}

In this subsection, we will analyze the application of AHP approach in various disciplines. Tab. 1 shows that the students of management science and engineering, and business administration are more like to use AHP approach. It is note that business administration includes master of business administration (MBA), executive master of business administration (EMBA), master of professional accounting (MPAcc), enterprise management, and technology economy \& management. The students of engineering management, industrial engineering, and computer science and technology are often to use approach.

Tab.1 AHP approach in various disciplines

\begin{tabular}{lclc}
\hline Disciplines & Number & Disciplines & Number \\
\hline Management Science and Engineering & 29 & Transportation Engineering & 3 \\
Business Administration & 25 & Mechanical Engineering & 2 \\
Engineering Management & 14 & Journalism and Communication & 2 \\
Industrial Engineering & 12 & Logistics Engineering & 2
\end{tabular}

\footnotetext{
${ }^{1}$ See http://www.lib.tsinghua.edu.cn/database/th disser.htm, (last retrieved 05/31/2018).
} 


\begin{tabular}{lclc} 
Computer Science and Technology & 11 & Electrical Engineering & 2 \\
Engineering & 11 & Mathematical & 2 \\
Nuclear Science and Technology & 10 & Management & 2 \\
Control Science and Engineering & 9 & Software Engineering & 1 \\
Environmental Science and Engineering & 8 & Philosophy & 1 \\
Safety Engineering & 8 & Instrument Science and Technology & 1 \\
Hydraulic Engineering & 7 & Civil Engineering & 1 \\
Public Administration & 4 & Educational Technology & 1 \\
Mechanics & 4 & Biomedical Engineering & 1 \\
Economics & 3 & Total & 176 \\
\hline
\end{tabular}

\subsection{Application industries}

Tab. 2 shows that AHP approach applied to various industries. We can find that the method has been widely applied in the industries of construction, manufacturing, transportation, warehouse and logistics, information transmission, software, and information technology service.

Tab.2 AHP approach in various industries

\begin{tabular}{|c|c|c|c|}
\hline Industry & Number & Industry & Number \\
\hline Construction & 30 & Air Transport & 2 \\
\hline Civil Engineering & 9 & Road Transport & 1 \\
\hline Building Construction & 6 & Water Transport & 2 \\
\hline Building Installation & 3 & $\begin{array}{l}\text { Hydraulic Engineering and } \\
\text { Environmental Management }\end{array}$ & 15 \\
\hline Building Decoration & 1 & $\begin{array}{l}\text { Ecological and Environmental } \\
\text { Protection }\end{array}$ & 12 \\
\hline Others & 11 & Hydraulic Engineering & 2 \\
\hline Manufacturing & 27 & $\begin{array}{l}\text { Electricity and Water Supply } \\
\text { Industry }\end{array}$ & 12 \\
\hline Automobile Making & 5 & Electricity Supply & 10 \\
\hline Communication Equipment & 4 & Water Supply & 2 \\
\hline Specialized Equipment & 4 & $\begin{array}{l}\text { Public Management and Social } \\
\text { Security }\end{array}$ & 9 \\
\hline Mechanical Manufacturing & 2 & Public Management & 6 \\
\hline Food Processing & 1 & Social Security & 3 \\
\hline Electronic Equipment & 1 & Health care & 6 \\
\hline Power Equipment & 1 & Financial & 5 \\
\hline General Equipment & 1 & Journalism & 4 \\
\hline Others & 8 & Oil, Gas and Coal & 3 \\
\hline $\begin{array}{l}\text { Information Transmission, } \\
\text { Software, and Information } \\
\text { Technology Service }\end{array}$ & 24 & Business Service & 2 \\
\hline Software \& IT & 17 & Retail & 1 \\
\hline Internet and Related Service & 5 & Real estate & 1 \\
\hline Telecommunication & 2 & Accommodation & 1 \\
\hline
\end{tabular}


Transportation

and

23

1

Warehousing Logistics

Rail Transport

Warehousing Logistics

* Others mean the papers study a comprehensive problem involved various industries.

\subsection{Application fields}

From Tab. 3, we can find the application of AHP approach in various areas or field. In the field of product development and design, AHP approach is mainly applied to software development. In the field of engineering project, AHP approach has been applied for project selection, evaluation and rank. For management application, such as risk, quality, and safety management, AHP approach is also often used for ranking, selection, evaluation, analysis, and decision making process.

Tab. 3 AHP approach in various areas/fields

\begin{tabular}{cccc}
\hline Area/Field & Number & Area/Field & Number \\
\hline Product Development and Design & 22 & Enterprise Strategy & 4 \\
Engineering Project & 21 & Marketing Analysis & 4 \\
Risk Management & 14 & Competitive Strength Evaluation & 3 \\
Vendor Selection & 14 & Organization Structure Design & 3 \\
Impact Evaluation & 12 & Employee Management & 3 \\
Quality Management & 10 & Purchasing Management & 3 \\
Safety Management & 10 & Financial Management & 2 \\
Performance Evaluation & 9 & Cost Management & 2 \\
Investment Decision & 8 & Process Optimization & 2 \\
Economic Benefit & 6 & resource allocation & 1 \\
Efficient Evaluation & 5 & Credit Management & 1 \\
Operations Management & 5 & Education Management & 1 \\
Project Management & 4 & Inventory Management & 1 \\
Supply Chain Management & 4 & Total & 176 \\
\hline
\end{tabular}

\section{Conclusions}

In this paper, we analyze the application of AHP based on the cases of doctoral and master theses colleting from Tsinghua University. The main points of this paper can be concluded as follows: 1) AHP approach is gaining growing popularity comparing with other MCDM approaches; 2) the students of business administration and management science and engineering are more like to use AHP approach; 3) AHP approach has been applied to various industries like construction, manufacturing, transportation, warehouse and logistics; 4) In the fields of engineering project and product development and design, AHP approach is often used as one of research tools. It is necessary to research the characters and limitations of application of AHP.

\section{References}

Davies, M. (2001). Adaptive AHP: A Review of Marketing Applications with Extensions. European Journal of Marketing, 35(7/8), 872-894. 
Russo, R. D. F. S. M., \& Camanho, R. (2015). Criteria in AHP: A Systematic Review of Literature. Procedia Computer Science, 55, 1123-1132.

Saaty, T.L. (1980), The Analytic Hierarchy Process, McGraw-Hill, New York, NY.

Singh, B. (2016). Analytical Hierarchical Process (AHP) and Fuzzy AHP Applications - A Review Paper. International Journal of Pharmacy \& Technology, 8(4), 4925-4946.

Triantaphyllou, E. (2000). Multi-criteria Decision Making Methods: A Comparative Study. Springer, Boston, MA. 